\title{
ACTITUDES Y PERCEPCIONES DE LOS ESTUDIANTES, DOCENTES Y DIRECTIVOS SOBRE ENSEÑANZA Y APRENDIZAJE FLEXIBLES, E INCORPORACIÓN DE TIC
}

\section{ATTITUDES AND PERCEPTIONS OF STUDENTS, TEACHERS AND DIRECTORS ON FLEXIBLE TEACHING AND LEARNING, AND INCORPORATION OF ICT}

\author{
José J. Ñáñez ${ }^{1}$, Juan C. Solano²., Edwin Bernal³. \\ Recibido para publicación: 14 de septiembre 2016 - Aceptado para publicación: 10 de octubre 2016
}

\section{RESUMEN}

La construcción de ambientes digitales de aprendizaje es uno de los retos contemporáneos de la modalidad a distancia en la educación superior colombiana. Lo es en mayor medida para los programas académicos en formación inicial docente, al encontrarse ante un principio de flexibilidad que supone escenarios de aprendizaje sustentados en la mediación tecnológica, y que a su vez, modifican la relación entre docente y estudiante. En el presente artículo se da cuenta de las actitudes y percepciones que estudiantes, docentes y directivos poseen con relación a la enseñanza y el aprendizaje flexibles, y la incorporación de TIC en los procesos educativos. Se realizaron dos estudios exploratorios y correlacionales sobre actitudes de docentes y estudiantes, aplicando dos cuestionarios, y otros dos estudios exploratorios y descriptivos sobre percepciones de docentes y directivos, a través de entrevistas semiestructuradas. Aunque se reconoce la utilidad de las TIC, prevalece su uso instrumentalizado y la inseguridad frente a su potencial pedagógico y formativo.

PALABRAS CLAVE: Actitudes docentes. Percepciones docentes. Formación inicial docente. Educación a distancia. Uso y apropiación de las TIC.

\begin{abstract}
The construction of digital learning environments is one of the contemporary challenges of distance learning in Colombian higher education. It is more important for academic programs in initial teacher training, when faced with a principle of flexibility that assumes learning scenarios supported by technological mediation, and that in turn, modify the relationship between teacher and student. In this article, the attitudes and perceptions that students, teachers and managers have regarding flexible teaching and learning, and the incorporation of ICT in educational processes are presented. Two exploratory and correlational studies

\footnotetext{
${ }^{1}$ Doctor en Educación, Magíster en Educación, Licenciado en Filosofía y Educación Religiosa. Docente de planta adscrito al Departamento de Pedagogía y Mediaciones Tecnológicas, Universidad del Tolima. Ibagué, Tolima. Dirección: Campus Barrio Santa Elena Parte Alta, Bloque 31B, Piso 4. Teléfono: 2771212. Email: jinanezr@ut.edu.co

${ }^{2}$ Magíster en Tecnologías de Información Aplicadas a la Educación, Ingeniero de Sistemas. Docente de planta adscrito al Departamento de Pedagogía y Mediaciones Tecnológicas, Universidad del Tolima. Ibagué, Tolima. ${ }^{3}$ Tecnólogo en Automatización Industrial del Servicio de Educación Nacional -SENA-, Sede Manizales. Actualmente es estudiante de pregrado en Administración de Sistemas Informáticos de la Universidad Nacional de Colombia, Sede Manizales.

${ }^{4}$ Magíster en Tecnologías de Información Aplicadas a la Educación, Licenciado en Matemáticas y Computación. Docente de planta adscrito al Departamento de Psicopedagogía, Universidad del Tolima. Ibagué, Tolima.
} 
on the attitudes of teachers and students were carried out, applying two questionnaires, and two other exploratory and descriptive studies on perceptions of teachers and managers, through semi-structured interviews. Although the usefulness of ICT is recognized, its instrumentalized use and insecurity prevail over its pedagogical and formative potential.

KEY WORDS: Teachers' attitudes. Teachers' perceptions. Initial teacher training. Distance education. Use and appropriation of ICT.

\section{INTRODUCCIÓN}

En la formación inicial docente, FID, de la modalidad de educación a distancia de la Universidad del Tolima es escasa la apropiación y uso de ambientes digitales de aprendizaje, considerando la necesidad de desarrollar procesos más flexibles de enseñanza y aprendizaje. En consecuencia, se planteó el estudio Ambientes digitales para la formación inicial docente en la modalidad de educación a distancia de la Universidad del Tolima, con un enfoque cualitativo, desde la investigación acción (Elliott 2010). En este marco, el presente artículo pretende abordar la problemática desde el estudio de las actitudes y las percepciones que los docentes poseen con relación a la enseñanza y el aprendizaje flexibles, y la incorporación de TIC en los procesos educativos en la modalidad, como uno de los puntos de partida del proceso.

Las TIC en la formación docente constituye un ámbito de investigación reciente en América Latina, señalándose que "en líneas generales, estos estudios coinciden en que la situación no es auspiciosa, lo que se asocia no solamente a un problema regional sino que constituye una tendencia internacional" (Dussel et al. 2014). En el análisis de las tendencias en formación para la innovación educativa en Colombia se plantea que "la vinculación de [TIC] a los procesos de [FID], es considerada una de las problemáticas más representativas en la caracterización de la situación" (Ministerio de Educación Nacional 2013).

En cuanto al uso y apropiación de los recursos y herramientas educativas digitales por parte de los formadores de formadores, se revisaron algunos estudios cualitativos, cuantitativos o mixtos, con predominancia de los primeros, con alcance exploratorio, descriptivo o interpretativo (Gámiz 2009, Garrido 2009, Mellado 2010, Tobón et al. 2010, Guisao 2011, Careaga y Fuentes 2012, Díez
2012, Sánchez y Morales 2012, Torres 2012, Arias y Vanegas 2013, Cifuentes y Cerda 2013, Parra y Cardona 2013, Álvarez y Morán 2014, Fraga y Gewerc 2015, Garnica 2015, Hinojosa et al. 2015, Laura et al. 2015, Vera 2015). Se identificaron dos ejes: el primero, de las representaciones sobre el uso y la apropiación de las TIC en la FID, y el segundo, de las estrategias educativas implicadas en su uso y apropiación de las TIC en la FID. En tales estudios, se destaca la reflexión y la acción formativa que se derivan de cada uno de los entornos digitales en el proceso de enseñanza y aprendizaje, enmarcados en las transformaciones educativas que enfrenta la educación superior, en contextos específicos.

La formación flexible es una noción amplia que implica un cambio fundamental de las prácticas educativas centradas en el maestro a las prácticas centradas en el estudiante, hacia una enseñanza y un aprendizaje flexibles. Este cambio conlleva la generación de alternativas educativas en cuanto a tiempos, espacios, medios, contextos y modalidades de formación (Díaz 2003). La flexibilidad define una nueva concepción de los procesos de enseñar y aprender en la universidad, y esto demanda nuevos papeles y competencias de los profesores y de los estudiantes universitarios (Maldonado 2012).

La Organización de las Naciones Unidas para la Educación, la Ciencia y la Cultura, UNESCO (2008), plantea el diseño de programas de formación docente a través de tres enfoques (nociones básicas en TIC, profundización del conocimiento y generación del conocimiento), en relación con los componentes del sistema educativo: política y visión, plan de estudios y evaluación, pedagogía, TIC, organización y administración, y formación profesional.

Para la construcción de una ruta de formación docente la UNESCO propone partir de las necesidades, intereses y contexto, desde tres percepciones (amplitud, profundidad y 
funcionalidad). Tobón et al. (2010) plantearon la percepción de profundidad, al desarrollar tres componentes del sistema educativo (pedagogía, TIC y formación profesional de docentes), a través de los tres enfoques mencionados, considerando que existe una relación directa entre el objeto de estudio y los componentes del sistema educativo.

La percepción, a lo largo del tiempo, ha sido conceptualizada por diversas disciplinas de las ciencias sociales, con el fin de analizar las múltiples formas de interpretar un mismo fenómeno o una realidad, por parte de los individuos. La percepción para fines específicos de este análisis es entendida como "un permanente acto de conceptualización. Los eventos del mundo externo son organizados a través de juicios categoriales que se encargan de encontrar una cualidad que represente de la mejor manera posible a los objetos" (Oviedo 2004).

Particularmente, la percepción docente respecto a las TIC se puede explicar mediante tres categorías, de acuerdo a Riascos et al. (2009): una primera que refiere a la percepción docente de las $\mathrm{TIC}$, desde tres perspectivas (como herramienta imprescindible, importante o inútil), una segunda categoría en lo relativo al grado de utilización de las TIC por parte del docente (niveles alto, medio o bajo), y una tercera categoría enunciada como el impacto de las TIC en los procesos de aprendizaje (visto desde una perspectiva de aportes positivos o negativos).

A fin de complementar y precisar lo dicho por Quezada (2015), se retoma a Hooper y Rieber (1995) en lo relacionado con los niveles de apropiación de TIC de los docentes, quienes plantean la familiarización, utilización, integración, reorientación y evolución, como las formas en que se asumen estas herramientas en la labor académica.

\section{METODOLOGÍA}

Para identificar las actitudes que los docentes y los estudiantes poseen con relación a la enseñanza y el aprendizaje flexibles y la incorporación de TIC en los procesos educativos, se realizaron dos estudios de carácter exploratorio y correlacional. Sus puntos de indagación fueron las actitudes, los usos y los intereses de formación respecto a las TIC, para el primer caso, y las actitudes y los usos respecto a las TIC, para el segundo. En cada caso se aplicó un cuestionario, adaptados de Tobón et al. (2010), considerando el contexto de aplicación.

La población docente estuvo conformada por 118 docentes de la Universidad del Tolima, en el Semestre B de 2016, de los programas de formación inicial docente en modalidad de educación a distancia, Centro de Atención Tutorial, CAT Ibagué: Licenciatura en Ciencias Naturales y Educación Ambiental, Licenciatura en Educación Artística, Licenciatura en Literatura y Lengua Castellana, y Licenciatura en Pedagogía Infantil. La población estudiantil estuvo conformada por 1.356 estudiantes de la Universidad del Tolima, en el Semestre B de 2016, de los programas y CAT antes mencionados de formación inicial docente.

Para tal aplicación del cuestionario, se estimó la muestra de los docentes en 77, considerando un error del 5.5\%, una proporción de 0,5 y una confianza del $90 \%$, realizándose on line y off line, para lo cual se hizo difusión mediante redes sociales y correos electrónicos institucionales dirigidos a los docentes. De los 80 docentes que respondieron las preguntas, el $42,5 \%$ son de género femenino y el $57,5 \%$ de género masculino. Su edad está comprendida entre los 26 y 70 años, con una media de 46 años. De acuerdo con el nivel de formación, se ubican así: el $5 \%$ en el nivel de doctorado, el $60 \%$ de maestría, el 30\% de especialización y el 5\% de pregrado. El 19\% de los encuestados alcanza una experiencia docente de 1 a 5 años, mientras que el $21 \%$ está en el rango de 5 a 10 años, el 30\% de 10 a 15 años y el $30 \%$ restante de 15 años en adelante. Respecto al tipo de vinculación, el $87,5 \%$ son profesores catedráticos y el $12,5 \%$ son profesores de planta.

Para la aplicación de los cuestionarios, se estimó la muestra de los estudiantes en 192, considerando un error del 5.5\%, una proporción de 0,5 y una confianza del 90\%. La aplicación del cuestionario se realizó on line y off line, para lo cual se hizo difusión mediante redes sociales y correos electrónicos institucionales dirigidos a todos los estudiantes de licenciatura en la modalidad. De los 193 estudiantes que respondieron la encuesta, el $78,2 \%$ son de género femenino y el $21,8 \%$ de género masculino, y su edad está comprendida entre los 16 y 54 años, con una media de 27 años. De acuerdo al programa en que se están formando, el $15,5 \%$ estudian Licenciatura en Ciencias Naturales y Educación Ambiental, el 26,9\% 
Licenciatura en Educación Artística, el 26,4\% Licenciatura en Literatura y Lengua Castellana y el 31,1\% Licenciatura en Pedagogía Infantil. Según el semestre, el 38,8\% de los estudiantes cursan semestres $1 \circ 2$, el 7,8\%, semestres $3 \circ 4$, el $25,4 \%$, semestres 5 o 6 , el 22,8\%, semestres 7 o 8 , y el $5,7 \%$, semestres 9 o 10. El $88,6 \%$ de los estudiantes expresa afirmativamente tener acceso a computador propio, en tanto que el $11,4 \%$ negativamente. Para acceder a Internet, el 82,9\% de los estudiantes lo hace en su vivienda, el 9,3\% en un café y el $7,8 \%$ en la Universidad, mediante el móvil o en sus circunstancias laborales.

Para identificar las percepciones que los docentes poseen con relación a la enseñanza y el aprendizaje flexibles y la incorporación de TIC en los procesos educativos, se realizó un estudio de carácter exploratorio y descriptivo, de corte cualitativo, sobre las percepciones respecto a las TIC y los niveles de apropiación de las mismas. Lo anterior, realizando entrevistas semiestructuradas (Valles 2007) a dos docentes de cada programa antes mencionado.

Los docentes que participaron en la muestra intencional cumplieron con los siguientes criterios de selección: ser profesores de planta o catedráticos, que pertenecieran a uno de los programas de formación inicial docente del IDEAD en el CAT Ibagué, que orientaran cursos del núcleo de formación pedagógica, y tuvieran formación específica a fin al programa. Además, los profesores debían conocer las dinámicas académicas de éste, pertenecer o haber pertenecido al comité curricular del mismo, y participar o haber participado en procesos de evaluación y acreditación del programa.

El análisis de las entrevistas se basó en los planteamientos sobre percepciones respecto a las TIC de Riascos et al. (2009), y sobre apropiación de TIC de Hooper y Rieber (1995), referidos en apartados anteriores.

Para identificar las percepciones sobre la incorporación de TIC que poseen los directivos de programas de licenciatura, se realizó un estudio de carácter exploratorio y descriptivo, de corte cualitativo, se realizó entrevista semiestructurada a la directora de cada uno de los cuatro programas antes mencionados. Los resultados de las entrevistas realizadas se expresan conforme a cinco ítems desarrollados a través de las preguntas formuladas. Dichos ítems, permiten caracterizar la presencia de las TIC, su uso y apropiación dentro de los currículos de los programas académicos señalados.

\section{RESULTADOS Y DISCUSIÓN}

\subsection{La perspectiva de los docentes (actitudes) sobre la incorporación de TIC en la enseñanza y el aprendizaje flexibles}

Los docentes, como su puede corroborar en la tabla 1, donde se presenta la correlación de variables estudiadas, presentan una actitud positiva frente a las TIC. Los de menor edad y menor experiencia presentan una mejor actitud. En los componentes afectivo, comportamental y cognitivo, por ejemplo, se evidencia un alto grado de homogeneidad. Los docentes presentan mejor actitud en el componente afectivo que en el cognitivo y el comportamental, y a su vez, mejor actitud en el cognitivo que en el comportamental. Esto es indicador de unos sentimientos que favorecen la incorporación de TIC en el proceso formativo, que propician una representación clara respecto a dicha incorporación, y una acción poco definida. Los docentes con mejor actitud hacia las TIC presentan más frecuencia de uso de TI y mayor experticia en TC para el desarrollo de su labor educativa.

En consecuencia, los docentes experimentan con regularidad el uso de nuevos recursos o herramientas digitales en el desarrollo de estrategias de trabajo académico en sus cursos (Ítem 13) y sienten interés por desempeñar un papel de liderazgo en la formación, basada en la innovación y el aprendizaje permanente, enriquecidos por TIC (Ítem 15).

Así mismo, los docentes consideran que las estrategias de trabajo académico mediadas por TIC contribuyen a resolver problemas de la vida real (Ítem 12). Ello indicaría, la necesidad de fomento y consolidación de comunidades de aprendizaje y de práctica de los docentes, que permitan a su vez estimular el desarrollo de competencias básicas, intermedias y avanzadas, que tengan en cuenta dimensiones pedagógicas, comunicativas, investigativas y tecnológicas, con relación a la integración del TIC en el proceso formativo de la modalidad. Todo ello indicaría el significado y el sentido de las competencias 
Tabla 1. Correlaciones de las variables estudiadas

\begin{tabular}{|c|c|c|c|c|c|c|c|c|}
\hline & & Edad & AEES & ATIC & FUTI & IATI & ETC & IATC \\
\hline \multirow{3}{*}{ Edad } & $\begin{array}{l}\text { Correlación de } \\
\text { Pearson }\end{array}$ & 1 & ,602" & ,018 &,$- 293^{* *}$ & ,135 &,$- 408^{* *}$ & ,207 \\
\hline & Sig. (bilateral) & & ,000 & ,873 & ,008 & ,233 & ,000 & 065 \\
\hline & $\mathrm{N}$ & 80 & 80 & 80 & 80 & 80 & 80 & 80 \\
\hline \multirow{3}{*}{$\begin{array}{l}\text { Años de experiencia en } \\
\text { educación superior }\end{array}$} & $\begin{array}{l}\text { Correlación de } \\
\text { Pearson }\end{array}$ & ,602** & 1 & ,048 &,- 052 & ,078 &,- 156 & ,065 \\
\hline & Sig. (bilateral) &, 000 & & ,675 & ,646 & ,492 & , 168 & ,566 \\
\hline & $\mathrm{N}$ & 80 & 80 & 80 & 80 & 80 & 80 & 80 \\
\hline \multirow{3}{*}{ Actitud hacia las TIC } & $\begin{array}{l}\text { Correlación de } \\
\text { Pearson }\end{array}$ & 018 & ,048 & 1 & , 178 & ,118 & ,382** & ,025 \\
\hline & Sig. (bilateral) & ,873 & ,675 & & ,115 & ,298 &, 000 & ,828 \\
\hline & $\mathrm{N}$ & 80 & 80 & 80 & 80 & 80 & 80 & 80 \\
\hline \multirow{3}{*}{$\begin{array}{l}\text { Frecuencia de uso de } \\
\text { las TI }\end{array}$} & $\begin{array}{l}\text { Correlación de } \\
\text { Pearson }\end{array}$ &,$- 293^{* *}$ &,- 052 &, 178 & 1 & ,138 & ,603** &,- 138 \\
\hline & Sig. (bilateral) & ,008 & ,646 &, 115 & & ,223 & ,000 & ,221 \\
\hline & $\mathrm{N}$ & 80 & 80 & 80 & 80 & 80 & 80 & 80 \\
\hline \multirow{3}{*}{$\begin{array}{l}\text { Interés de aprendizaje en } \\
\text { las } \mathrm{TI}\end{array}$} & $\begin{array}{l}\text { Correlación de } \\
\text { Pearson }\end{array}$ & , 135 & ,078 & ,118 & , 138 & 1 & ,076 & ,489** \\
\hline & Sig. (bilateral) & ,233 & ,492 & ,298 & ,223 & & ,502 & ,000 \\
\hline & $\mathrm{N}$ & 80 & 80 & 80 & 80 & 80 & 80 & 80 \\
\hline \multirow{3}{*}{ Experticia en las TC } & $\begin{array}{l}\text { Correlación de } \\
\text { Pearson }\end{array}$ &,$- 408^{* *}$ &,- 156 & ,382** &, $603^{* *}$ & ,076 & 1 &,- 071 \\
\hline & Sig. (bilateral) & ,000 & , 168 & ,000 & ,000 & ,502 & & ,532 \\
\hline & $\mathrm{N}$ & 80 & 80 & 80 & 80 & 80 & 80 & 80 \\
\hline \multirow{3}{*}{$\begin{array}{l}\text { Interés de aprendizaje en } \\
\text { las TC }\end{array}$} & $\begin{array}{l}\text { Correlación de } \\
\text { Pearson }\end{array}$ & ,207 & ,065 & 025 &,- 138 & ,489** &,- 071 & 1 \\
\hline & Sig. (bilateral) & ,065 & ,566 & ,828 & ,221 & ,000 & ,532 & \\
\hline & $\mathrm{N}$ & 80 & 80 & 80 & 80 & 80 & 80 & 80 \\
\hline
\end{tabular}

Fuente: Autores.

informacionales, más allá de las competencias informáticas, en la transformación de las prácticas tutoriales y las prácticas docentes en los procesos de formación inicial.

los docentes señalan su interés en desempeñar un papel de liderazgo en la formación con sus colegas, basada en la innovación y el aprendizaje permanente, enriquecidos por TIC, favoreciendo con ello su disposición, así como la de sus estudiantes en formación inicial, para facilitar y potenciar su práctica tutorial y su práctica docente, de manera respectiva. Esto favorecería, a su vez, la consideración de la importancia que tiene para el desarrollo de los cursos el conocer la utilización de herramientas para elaborar materiales que ayuden al estudiante a comprender problemas complejos. Lo anterior, indicaría la necesidad de fortalecer procesos de formación de los docentes, orientados al desarrollo de competencias en la integración de TIC que potencien el trabajo autónomo del profesor, como también su acompañamiento y apoyo.

3.2. La perspectiva de los estudiantes (actitudes) sobre la incorporación de TIC en la enseñanza y el aprendizaje flexibles

Los estudiantes presentan una actitud positiva 
José J. Ñáñez, ACTITUDES Y PERCEPCIONES SOBRE ENSENANZA Y APRENDIZAJE FLEXIBLES

Tabla 2. Percepciones respecto a las TIC y niveles de apropiación de TIC identificados

\begin{tabular}{|c|c|c|c|}
\hline Docentes entrevistados & \multicolumn{2}{|c|}{$\begin{array}{l}\text { Percepciones respecto a las TIC } \\
\text { (Riascos et al., 2009) }\end{array}$} & $\begin{array}{l}\text { Niveles de apropiación de TIC } \\
\text { (Hooper y Rieber, 1995) }\end{array}$ \\
\hline \multirow{3}{*}{$\begin{array}{l}\text { Licenciatura en } \\
\text { Ciencias Naturales y } \\
\text { Educación Ambiental }\end{array}$} & Percepción docente & Importante & \multirow{3}{*}{ Integración } \\
\hline & Grado de utilización & Alto & \\
\hline & Impacto de las TIC & Positivo & \\
\hline \multirow{3}{*}{$\begin{array}{l}\text { Licenciatura en } \\
\text { Literatura y Lengua Castellana }\end{array}$} & Percepción docente & Importante & \multirow{3}{*}{ Familiarización } \\
\hline & Grado de utilización & Medio & \\
\hline & Impacto de las TIC & Positivo & \\
\hline \multirow{3}{*}{$\begin{array}{l}\text { Licenciatura en } \\
\text { Pedagogía Infantil }\end{array}$} & Percepción docente & Importante & \multirow{3}{*}{ Integración } \\
\hline & Grado de utilización & Alto & \\
\hline & Impacto de las TIC & Positivo & \\
\hline \multirow{3}{*}{$\begin{array}{l}\text { Licenciatura en } \\
\text { Educación Artística }\end{array}$} & Percepción docente & Importante & \multirow{3}{*}{ Utilización } \\
\hline & Grado de utilización & Alto & \\
\hline & Impacto de las TIC & Positivo & \\
\hline
\end{tabular}

Fuente: Autores.

frente a las TIC, la cual está fuertemente correlacionada en forma positiva con la experticia en TIC y medianamente relacionada con la frecuencia de uso de TI. La frecuencia de uso de TI y la experticia en TC están fuertemente correlacionadas con el semestre. En los componentes afectivo, comportamental y cognitivo se evidencia un alto grado de homogeneidad. Los estudiantes presentan mejor actitud en el

Tabla 3. Correlaciones de las variables estudiadas

\begin{tabular}{|c|c|c|c|c|c|c|}
\hline & & Edad & Semestre & ATIC & FTI & ETC \\
\hline \multirow{3}{*}{ Edad } & Correlación de Pearson & 1 &, $328^{* *}$ & ,104 &, 008 &,- 083 \\
\hline & Sig. (bilateral) & &, 000 & ,149 & ,913 & ,251 \\
\hline & $\mathrm{N}$ & 193 & 193 & 193 & 193 & 193 \\
\hline \multirow{3}{*}{ Semestre } & Correlación de Pearson &, $328^{* *}$ & 1 & ,125 &, $235^{\star \star}$ &, $156^{*}$ \\
\hline & Sig. (bilateral) &, 000 & &, 084 &, 001 & ,030 \\
\hline & $\mathrm{N}$ & 193 & 193 & 193 & 193 & 193 \\
\hline \multirow{3}{*}{ Actitud hacia las TIC } & Correlación de Pearson & ,104 & ,125 & 1 &, $163^{*}$ &, $266^{\star \star}$ \\
\hline & Sig. (bilateral) & ,149 &, 084 & &, 024 &, 000 \\
\hline & $\mathrm{N}$ & 193 & 193 & 193 & 193 & 193 \\
\hline \multirow{3}{*}{ Frecuencia de uso de las TI } & Correlación de Pearson &, 008 &, $235^{\star *}$ &, $163^{*}$ & 1 &, $575^{\star *}$ \\
\hline & Sig. (bilateral) & ,913 &, 001 & 024 & &, 000 \\
\hline & $\mathrm{N}$ & 193 & 193 & 193 & 193 & 193 \\
\hline \multirow{3}{*}{ Experticia en las TC } & Correlación de Pearson &,- 083 &, $156^{*}$ &, $266^{\star \star}$ &, $575^{\star \star}$ & 1 \\
\hline & Sig. (bilateral) & ,251 &, 030 &, 000 &, 000 & \\
\hline & $\mathrm{N}$ & 193 & 193 & 193 & 193 & 193 \\
\hline \multicolumn{7}{|c|}{ **. La correlación es significativa en el nivel 0,01 (bilateral). } \\
\hline \multicolumn{7}{|c|}{ *. La correlación es significativa en el nivel 0,05 (bilateral). } \\
\hline
\end{tabular}

De igual manera, se puede evidenciar el modo en que se da mayor consideración del trabajo orientado presencial, el cual puede enriquecerse componente cognitivo que en el comportamental y el afectivo, a su vez, mejor actitud en el comportamental que en el afectivo. De otra manera, una representación que favorece la incorporación de TIC en el proceso formativo, propicia una acción medianamente orientada, y unos sentimientos poco definidos, situaciones que se pueden evidenciar en la siguiente tabla: 
independiente. También indicaría la necesidad de fortalecer la comunicación entre los estudiantes como también el seguimiento y el acompañamiento requerido por ellos, lo que corresponde al trabajo orientado no presencial y al trabajo independiente. Podría pensarse que el estudiante asume el reto y la posibilidad de integración de TIC en el presente futuro de su práctica docente, frente a su forma de actuar y pensar en su proceso formativo en la modalidad.

Lo anterior, plantea para la institución, los docentes y directivos, la necesidad de fortalecer la competencia digital de los estudiantes, máxime si se tiene en cuenta que:

- Los estudiantes consideran que solo es posible tener una buena retroalimentación a través de una interacción cara a cara con el profesor (Ítem 2), y en el mismo sentido, que discutir en foros virtuales deja pocas enseñanzas, se logran mejores aprendizajes si la discusión se hace en persona (Ítem 4). Además, en correlación con éste último, consideran que las TIC son una herramienta que no cambia su actuar como futuro docente.

- A los estudiantes les parece incómodo el trabajo en red con sus compañeros (Ítem 20) y de igual manera, consideran que solo en algunos cursos y temas es posible utilizar las TIC en los procesos de enseñanza y aprendizaje (Ítem 17).

- Los estudiantes manifiestan su baja iniciativa en utilizar herramientas especializadas de búsqueda para ampliar la información de sus cursos (Ítem 12), así como su dificultad para saber qué hacer o con qué interactuar en el curso cuando el profesor utiliza recursos o herramientas educativas digitales (Ítem 13).

Por tanto, afirman que la incorporación de TIC hace que el profesor deba utilizar otros criterios y procesos de evaluación, además de los tradicionales. En consecuencia, los estudiantes expresan interés en hacer uso de las TIC en su práctica docente y posiblemente en su labor como futuros docentes. Ello indicaría la relevancia del uso y apropiación de TIC en las prácticas pedagógicas en la modalidad de educación a distancia, que centradas en los procesos de aprendizaje implican retos tanto al profesor como al estudiante, orientados al mejoramiento de la calidad de dichos procesos.

\subsection{Percepciones sobre la incorporación de TIC que poseen los directivos de programas de licenciatura}

La aplicación se construyó mediante el uso de la metodología de desarrollo ágil SCRUM [16]. En la cual se define la realización de reuniones de control para la definición de funcionalidades y la presentación de avances en la ejecución. La metodología permitió generar un proceso progresivo en función de los objetivos planteados en cada reunión, brindando al desarrollador flexibilidad y adaptabilidad ante los errores y nuevas necesidades que surgían durante la construcción del recurso educativo.

El recurso, se encuentra estructurado con un arreglo unidimensional, donde cada valor del arreglo hace referencia a una seña. Se compara el valor del arreglo con el nombre del avatar correspondiente, una vez encontrado, se presenta el avatar en pantalla. En cuanto al componente técnico, para el desarrollo del recurso educativo, se realizaron las siguientes tareas.

\subsubsection{Representación de la seña}

Con el fin de mejorar el rendimiento de los recursos de procesamiento computacional, se optó por la utilización de imágenes secuenciales para la construcción de cada seña, la cual está formada por una secuencia de 13 imágenes en formato jpg que por medio de movimientos secuenciales forman la seña. Las imágenes corresponden al avatar virtual proporcionado de forma gratuita por la fundación HETAH. Para lograr el movimiento de las imágenes se creó un algoritmo en Javascript que realiza la animación. Este algoritmo carga la imagen respectiva posicionándola en dimensiones predefinidas y luego realiza cambios en las posiciones a través del atributo utilizado con CSS backgroundPosition, el cual fluctúa con la modificación de algunas banderas que incrementan según una función cíclica controlada con el evento tiempo específico de Javascript, el cual cuenta con intervalos de dos segundos de ejecución por cada seña. La configuración de estos tiempos debe ser adecuada con el fin de que el usuario tenga posibilidades de detallar la secuencia de movimientos para comprender y asimilar la seña. 


\subsubsection{Elección de material visual}

Las imágenes utilizadas fueron tomadas de repositorios libres y también algunas son propias, las cuales corresponden a fotografías de los objetos reales.

\subsubsection{Requerimientos de operación}

Basados en la experiencia adquirida por los desarrolladores, y debido a que se pretende ofrecer recurso educativo web, se optó por utilizar lenguajes de programación libres como lo son javascript, html y css.

\section{CONCLUSIONES}

Luego de haber hecho el ejercicio comprensivo respecto a las percepciones y los niveles de apropiación de las TIC a través de las entrevistas a docentes, estudiantes y directivas de las licenciaturas, es posible concluir lo siguiente:

- Los docentes de educación inicial del IDEAD de la Universidad del Tolima, en Ibagué, muestran claras señales que los posicionan en el nivel de Utilización en cuanto al uso y apropiación de TIC en las prácticas curriculares propias de su función docente, y en concordancia con la propuesta de Hooper y Rieber (1995).

- En la percepción docente se plantea que el uso de TIC por parte de los estudiantes es superficial, y con pocos fines poco académicos. Según ellos, se evidencia el desconocimiento en la búsqueda de información pertinente, y se pone de relieve la necesidad de un proceso de sensibilización para lograr un uso de TIC en función de los propósitos formativos planteados.

- De igual manera, los docentes entrevistados reconocen la importancia del uso de mediaciones tecnológicas en los procesos educativos, aunque persisten métodos tradicionales de enseñanza basados en los encuentros presenciales, y la transmisión magistral del conocimiento. Esto, genera divergencias con el modelo de educación a distancia planteado por la Institución.

- Los estudiantes presentan una actitud positiva frente a las TIC, la cual está fuertemente correlacionada en forma positiva con la experticia en TC y medianamente relacionada con la frecuencia de uso de $\mathrm{TI}$.

- Respecto a la frecuencia de uso y a la experticia por parte de los estudaintes para las TI, la frecuencia de uso por parte de los estudiantes es ocasional y para las TC el nivel de experticia es intermedio. La frecuencia de uso de TI está relacionado con la experticia en TC, lo que quiere decir que los estudiantes con mayor experticia en TC hacen más usos de las TI.

- Las consideraciones que tuvieron lugar de parte de las directiva, permitieron identificar la manera en que las TIC son empleadas dentro de la ejecución de los currículos y prácticas de aula de las licenciaturas. Se evidenció que dentro de los principales inconvenientes que han impedido una presencia significativa, transversal y articulada de las TIC en los planes de estudio, se encuentra que ello depende de la voluntad del docente para implementarlas en su microcurrículo, y de las actividades que puedan establecer una relación entre las TIC y las disciplinas propias de cada programa académico.

- Finalmente, según las directoras, tanto estudiantes como profesores mantienen principalmente un vínculo lúdico con las TIC, sin contemplar una percepción académica de sus posibilidades, o reconocer su potencial formativo y didáctico para nutrir los procesos de enseñanza-aprendizaje. Igualmente, se cree que las TIC son un asunto que le compete solo a los profesionales afines a estas áreas, desconociendo la dinamización que pueden ofrecer en el direccionamiento de los encuentros presenciales y no presenciales. Las directoras, por su parte, reconocen la pertinencia de emprender planes de mejoramiento y dar lugar a la construcción de lineamientos que le otorguen a las TIC un mayor protagonismo dentro de los currículos, no solo por estar a la vanguardia o cumplir una disposición institucional, sino con el propósito de diversificar los métodos de aprendizaje, los recursos y las relaciones entre docentes y estudiantes, cualificándolos para el ámbito educativo y el ejercicio de su profesión.

\section{AGRADECIMIENTOS}

Los autores agradecen a la fundación HETAH por Hacemos un reconocimiento a la contribución hecha a los estudios por parte de July Lizeth Bolívar Rodríguez, Comunicadora Social Periodista y Magister en Educación; Paula 
Leal Pérez, Profesional en Ciencias Sociales, candidata a Magister en Educación y John James Otavo Velázquez, Profesional en Matemáticas y Estadística.

\section{REFERENCIAS}

[1]. Álvarez, G. y Morán, L. ¿Cómo se dispone a los docentes para futuras prácticas con tecnologías? RED, Revista de Educación a Distancia, Universidad de Murcia, ISSN: 1578-7680 (en línea), 13(43), 2014. http:// www.um.es/ead/red/.

[2]. Arias, R. yVanegas, H. 2013. Caracterización de los procesos de implementación y uso de las aulas virtuales en la Facultad de Educación. En: Sánchez, J. (Ed), Nuevas ideas en informática educativa. Memorias del XVII Congreso Internacional de Informática Educativa, TISE. Universidad de Chile, Chile, p343-352.

[3]. Careaga, M. y Fuentes, C. 2012. Contexto mixto de aprendizaje con apoyo de tutoría virtual para estudiantes de la carrera de pedagogía en educación media en lenguaje y comunicación - UCSC - Chile. En: Sánchez, J. (Ed), Nuevas ideas en informática educativa. Memorias del XVII Congreso Internacional de Informática Educativa, TISE. Universidad de Chile, Chile, p254-263.

[4]. Cifuentes, G. y Cerda, C. Distancia entre percepción de uso de TIC y uso efectivo de campus virtual en académicos formadores de profesores. Revista Educación y Tecnología, Universidad Metropolitana de Ciencias de la Educación, ISSN: 0719-2495 (en línea), (2)3, 2013. http://revistas.umce. cl/index.php/edytec

[5]. Díaz, M. 2003. Flexibilidad y educación superior en Colombia. Instituto Colombiano para el Fomento de la Educación Superior, Colombia, 217p.

[6]. Díez, E. J. (2012). Modelos socioconstructivistas y colaborativos en el uso de las TIC en la formación inicial del profesorado. Revista de Educación 358:175-196.
[7]. Dussel, I. (Ed) 2014. Incorporación con sentido pedagógico de TIC en la formación docente de los países del Mercosur. Editorial Teseo, Argentina, 489p.

[8]. Elliott, J. (2010). La investigación-acción en educación. (6 ed.). Madrid, España: Morata.

[9]. Fraga, F. \& Gewerc, A. Creencias sobre Tecnología Educativa: una mirada desde la biografía escolar y universitaria de una maestra en formación inicial. RELATEC, Revista Latinoamericana de Tecnología Educativa, Universidad de Extremadura, ISSN: 1695-288X (en línea), 14(3), 2015. https://relatec.unex.es/

[10]. Gámiz, V. 2009. Entornos virtuales para la formación práctica de estudiantes de educación: implementación, experimentación y evaluación de la plataforma AulaWeb. Tesis Doctorado Fundamentos del Currículum y Formación del Profesorado en las áreas de Educación Primaria y Secundaria, Universidad de Granada, Granada.

[11]. Garnica, J. 2015. Nuevos "ambientes de aprendizaje" para viejas prácticas pedagógicas: el uso de Moodle en la Facultad de Educación de la Universidad de Cantabria. Trabajo Máster en Comunicación y Educación en la Red, Universidad Nacional de Educación a Distancia, Madrid

[12]. Garrido, J. 2009. Creencias sobre el rol de las tecnologías de información y comunicación en la formación inicial de docentes: explorando las diferencias entre estudiantes y docentes universitarios. Tesis Doctorado Diversidad y Cambio en Educación: Políticas y Prácticas, Universidad de Barcelona, Barcelona.

[13]. Guisao, G. 2011. Percepción de docentes y estudiantes en relación con el uso de las TIC en los procesos de enseñanzaaprendizaje. Trabajo de grado de Maestría en Educación, Universidad de Medellín, Medellín.

[14]. Hinojosa, V., Valdez, L., Servín, S. y Perusquía, E. 2015. La incorporación 
de las TIC en la práctica docente de los profesores del Sistema Universidad Abierta y Educación a Distancia de la Universidad Nacional Autónoma de México: Catálogo CUAED de herramientas colaborativas. XVI Encuentro Internacional Virtual Educa México. Organización de los Estados Americanos y Gobierno del Estado de Jalisco, Guadalajara, junio de 2015, 43p.

[15]. Hooper, S. y Rieber, L. (1995). Teaching with technology. En: Ornstein, A. (Ed), Teaching: theory into practice.. Allyn and Bacon, Estados Unidos, p154-170.

[16]. Laura, C., Sosa, O. y Almanza, L. 2015. Formación inicial docente y tecnologías: ¿cuáles son los niveles de integración de TIC en las prácticas pedagógicas universitarias?X Congreso sobre Tecnología en Educación \& Educación en Tecnología (TE \& ET). Red de Universidades con Carreras en Informática, Corrientes, junio de 2015, p247-257.

[17]. Maldonado, L. 2012. Virtualidad y autonomía. Pedagogía para la equidad. International Corporation of Network of Knowledge, Colombia.

[18]. Mellado, M. Portafolio en línea en la formación inicial docente. Revista Electrónica de Investigación Educativa, Instituto de Investigación y Desarrollo Educativo de la Universidad Autónoma de Baja California, ISSN: 1607-4041 (en línea), 12(1), 2010. http://redie.uabc.mx/.

[19]. Ministerio de Educación Nacional 2013. Competencias TIC para el desarrollo profesional docente. Ministerio de Educación Nacional, Colombia, 71p.

[20]. United Nations Educational, Scientific and Cultural Organization (2008). ICT Competency Standards for Teachers. Policy Framework. UNESCO, Francia.

[21]. Oviedo, G. L. (2004). La definición del concepto de percepción en psicología con base en la teoría Gestalt. Revista de Estudios Sociales 18:89-96.

[22]. Parra, L. y Cardona, C. 2013. Usos pedagógicos de las tecnologías de la información y la comunicación: en prácticas educativas formales en la educación superior. XII Foro de Investigadores de Informática Educativa Versión Internacional. Red Iberoamericana de Informática Educativa, Medellín, junio de 2013, 27p.

[23]. Quezada, C. 2015. Nivel de apropiación tecnológica con respecto al uso de recursos educativos abiertos en la enseñanza de la matemática a distancia en Costa Rica. En: Scott, P. y Ruíz, Á. (Ed), Educación Matemática en las Américas: 2015. Volumen 4: Uso de la Tecnología. Comité Interamericano de Educación Matemática, República Dominicana, p.349-360.

[24]. Sánchez, J. y Morales, S. Docencia universitaria con apoyo de entornos virtuales de aprendizaje (EVA). Digital Education Review, Grupo de Investigación Enseñanza y Aprendizaje Virtual y Observatorio de Educación Digital en la Universidad de Barcelona, ISSN 2013-9144 (en línea), 21, 2012. http://revistes.ub.edu/index.php/der.

[25]. Torres, J. (2012). Incidencia de Moodle en las prácticas pedagógicas en modalidad educativa B-Learning. Revista de Investigación, Desarrollo e Innovación 2(2):39-48.

[26]. Valles, M. 2007. Entrevistas cualitativas. Centro de Investigaciones Sociológicas, España, 201p.

[27]. Vera, C. 2015. Estrategias didácticas utilizadas en espacios académicos de educación abierta y a distancia. En: Sánchez, J. (Ed), Nuevas ideas en informática educativa. Memorias del XVII Congreso Internacional de Informática Educativa, TISE. Universidad de Chile, Chile, p431-434. 